Original Article

\title{
Relevance or plausibility? Health care and research recommendations
}

\section{Martien Brands}

Therapeutische Activiteiten Centrum Amsterdam. E-mail: martienbrands53@gmail.com

\begin{abstract}
Background: Several disease indications have been researched for homeopathic treatment. However, the degree of evidence of studies is not yet investigated for the whole of homeopathic care. Three levels of care are identified: 1 . Basic/ community health level. 2. Professional/ primary care level, 3. Advanced/ specialist care level
\end{abstract}

Methods: Browser searches were made to identify studies at the three levels; from major reviews the last 20 years. The degrees of evidence were further subdivided into the levels of care. Each care level was documented for 7 major areas of pathology: cardiovascular, respiratory, gastro intestinal, urogenital, Neuro-endocrino-immunological, infectious, degenerative-oncological diseases. Criteria for inclusion: for RCT's a minimum of Jadad score 3.

Results: A matrix yields an overview of studies of sufficient health services to integrate homeopathic treatment into th the included studies are performed at community health lev lity to make recommendations for ackage of service delivery. $75 \%$ of ly.

Discussion: A disproportionate segment of RCT's on commynity health level has been conducted, in relation to the actual teaching priorities on individual treatment in homeopathic practice, and professional profiling as 'specialists'. External and model validity enhancing recommendations for RCTs are provided, and some disease-cotegpries $w$ th suf icipht evidence presented.

Received: March, 2018. Accepted: April, 2018.

(C) International Journal of High Dilution Research.

Not for commercial purposes. 